\title{
Reassessment of 'Plesiosaurus' megacephalus (Sauropterygia: Plesiosauria) from the Triassic-Jurassic boundary, UK
}

\author{
Adam S. Smith
}

\begin{abstract}
The holotype specimen of 'Plesiosaurus' megacephalus Stutchbury, 1846 (BRSMG Cb 2335) was destroyed in an air raid on Bristol during WWII. The specimen comprised a complete skeleton from the Triassic-Jurassic boundary of Street-on-theFosse, Somerset, UK. Plaster casts of the skull and right forelimb produced prior to its destruction, in conjunction with historical photographs and original descriptions, provide three-dimensional anatomical data for a modern systematic diagnosis of the taxon. A previously proposed neotype specimen (LEICS G221.1851) is therefore regarded as a referred specimen. Detailed comparison with other Lower Jurassic plesiosaurians demonstrates that 'Plesiosaurus' megacephalus is a distinct taxon, separate from Rhomaleosaurus sensu stricto and Eurycleidus arcuatus, and so a new genus is erected to accommodate it: Atychodracon gen. nov. The clarification and description of Atychodracon megacephalus is a vital step towards understanding the diversity and resolving the systematics of large-bodied plesiosaurians from the Triassic-Jurassic boundary.
\end{abstract}

Adam S. Smith. Nottingham Natural History Museum, Wollaton Hall, Nottingham, NG8 2AE, UK. adam.smith@nottinghamcity.gov.uk

Keywords: new genus; Plesiosauria; Triassic-Jurassic; three-dimensional laser scan; plaster cast; Rhomaleosauridae

\section{INTRODUCTION}

Plesiosaurians (or plesiosaurs, clade Plesiosauria) are an extinct group of Mesozoic marine reptiles with a global fossil record that ranges from the Rhaetian (Latest Triassic) to the Maastrichtian (Latest Cretaceous) (O’Keefe, 2001). Plesiosaurs all have a broad body, four wing-like flippers, and a relatively short tail, but there is considerable diversity in their head and neck proportions (O'Keefe, 2002; O'Keefe and Carrano, 2005). The holotype of 'Plesiosaurus' megacephalus Stutchbury, 1846 (BRSMG Cb 2335), later reassigned to the genus Rhomaleosaurus (Cruickshank, 1994a), was one

http://zoobank.org/6311EDDA-8334-420E-A78D-5B16286CF4BE

PE Article Number: 18.1.20A

Copyright: Palaeontological Association April 2015

Submission: 9 August 2014. Acceptance: 31 March 2015

Smith, Adam S. 2015. Reassessment of 'Plesiosaurus' megacephalus (Sauropterygia: Plesiosauria) from the Triassic-Jurassic boundary, UK. Palaeontologia Electronica 18.1.20A: 1-19.

palaeo-electronica.org/content/2015/1146-plesiosaurus-megacephalus 


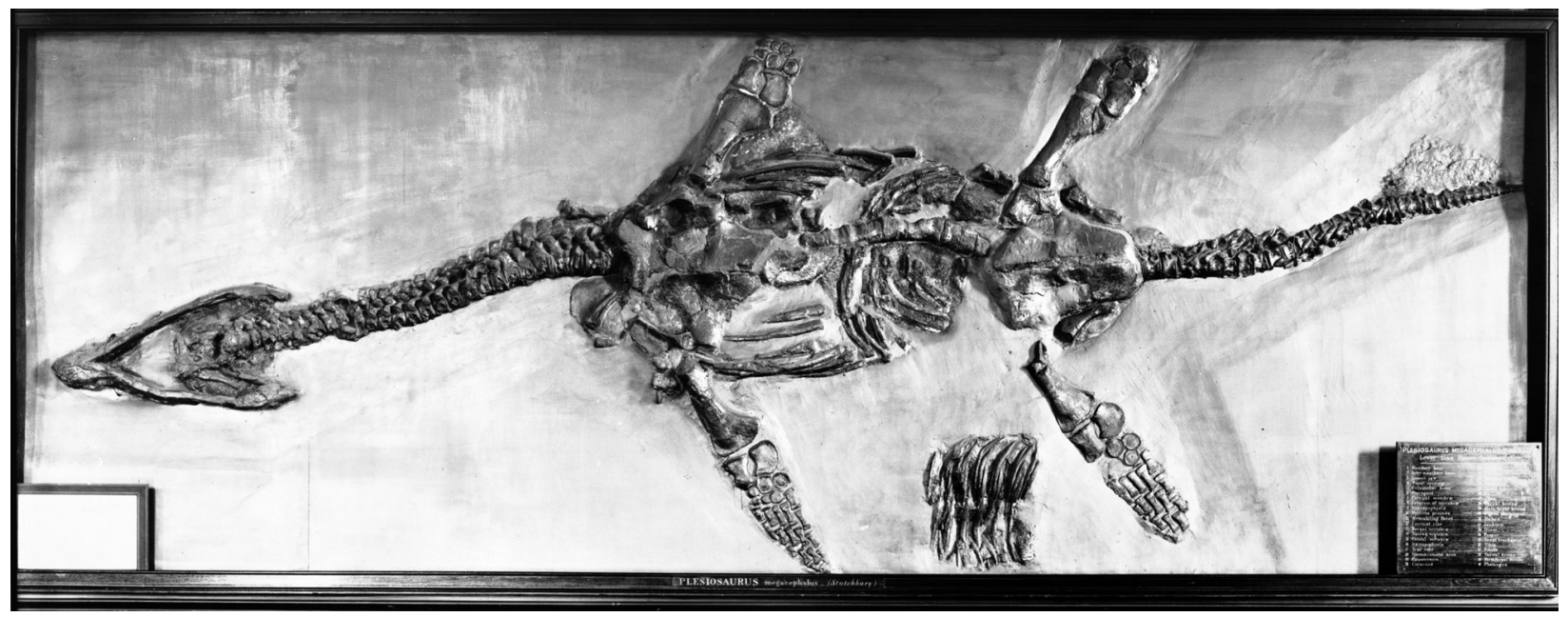

FIGURE 1. Historical photograph of the holotype skeleton (BRSMG Cb 2335) of Atychodracon megacephalus (Stutchbury, 1846). Photograph taken from glass plate negative in the Bristol City Museum \& Art Gallery, originally published by Swinton (1948). Bristol City Museum \& Art Gallery, reproduced with permission. Length of skeleton equals $4960 \mathrm{~mm}$.

of several plesiosaurian specimens displayed in the Bristol City Museum and Art Gallery during the first half of the twentieth century (Swinton, 1948) (Figure 1). This complete specimen was from the lowermost Hettangian of Street-on-the-Fosse (Cruickshank, 1994a; Storrs and Taylor, 1996), Somerset, UK. It was destroyed on the 24th November 1940 when the museum was struck in an air raid during the Second World War (Swinton, 1948). Original descriptions and illustrations of the specimen by Stutchbury (1846), Sollas (1881), and Swinton (1948), together with high quality historical photographs (Swinton, 1948), provide detailed information on the specimen. In addition, plaster casts of the skull and right forelimb of BRSMG Cb 2335 (Taylor and Cruickshank, 1989; Wyse Jackson, 2004) were produced before the specimen was destroyed. At least three casts of the holotype of 'Plesiosaurus' megacephalus are known, housed in the Natural History Museum, London (NHMUK R1309/1310); the Geology Museum, Trinity College Dublin (TCD.47762a, TCD.47762b; Wyse Jackson, 2004) and in the British Geological Survey, Keyworth, Nottingham (BGS GSM 118410). This paper provides a redescription and modern diagnosis of ' $P$.' megacephalus on the basis of the representative material of the destroyed holotype including the plaster casts. Detailed comparison with other Lower Jurassic plesiosaurians demonstrates that the taxon is generically distinct. Recent work on small-bodied plesiosaurians from the Triassic-Jurassic boundary (Benson et al., 2012, in press) has revealed higher diversity than previously realised. However, the large-bodied rhomaleosaurid plesiosaurians from the same horizon remain understudied. This paper is therefore a vital step towards understanding the diversity and evolutionary relationships of largebodied rhomaleosaurid plesiosaurians from the Triassic-Jurassic boundary, while also demonstrating the valuable role historical casts can play in systematic palaeontology.

\section{Institutional Abbreviations}

BGS, British Geological Survey, Keyworth, Nottingham; BRSMG, Bristol City Museum and Art Gallery; NHMUK, Natural History Museum, London, UK; NMING, National Museum of Ireland; LEICS, New Walk Museum, Leicester, UK; TCD, Geology Museum, Trinity College Dublin, Dublin, Ireland; WARMS, Warwickshire Museum, Warwickshire, UK.

\section{MATERIAL AND METHODS}

At least three casts of the holotype of 'Plesiosaurus' megacephalus are known, housed in the Natural History Museum, London (NHMUK R1309/ 1310); the Geology Museum, Trinity College Dublin (TCD.47762a, TCD.47762b; Wyse Jackson, 2004) and the British Geological Survey, Keyworth, Nottingham (BGS GSM 118410). Three-dimensional (3D) digital models of BGS GSM 118410 were produced in June 2014 as part of the JISC-funded 'GB3D fossil types online' project using a NextEngine HD PRO laser scanner on a tripod. Scan resolution was 'HD1' in the extended range for a 
typical point density of 2000 points per inch squared. Sufficient scans were taken to cover the entire specimen and then aligned manually within Scan Studio software. The aligned scans were remeshed with a 'simplify' setting of 0.0030 and a 'resolution ratio' of 0.6 . The software was set to fill minor holes in the new mesh where possible, and the final scans were exported to .PLY and .OBJ formats. These models provide a digital record of the cast material and are freely available to download from http://www.3d-fossils.ac.uk. Three separate 3D models were produced: a model of the entire skull and vertebrae as mounted (doi:10.5285/ 224dfa9f-d793-43ad-a454-6bd95f8b6eb2) model of the separate rostrum section (doi:10.5285/c10f5502-93fc-426a-91e0-

$7 \mathrm{cb} 13 \mathrm{a} 16 \mathrm{e} 52 \mathrm{c})$, and a model of the limb (doi:10.5285/c0261ad5-e4aa-409c-8cb7-

7d56c4810d48). Transverse cross-sections were produced from these models using 123D Make and Adobe Photoshop 3D tools, to visualise the 3D data in two dimensions.

\section{SYSTEMATIC PALAEONTOLOGY}

Superorder SAUROPTERYGIA Owen, 1860 Order PLESIOSAURIA de Blainville, 1835

Family RHOMALEOSAURIDAE Kuhn, 1961 Genus ATYCHODRACON gen. nov. zoobank.org/91560937-5FF5-4BA7-B09D-A96FFD35ADAE

Etymology. The name derives from the Greek aTUXńs (= atychis) meaning 'unfortunate', chosen because the holotype material of the type species was destroyed during a WWII air raid in 1940; and

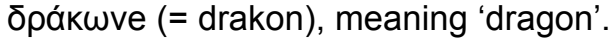

Type specimen. BRSMG Cb 2335 (destroyed). At least three partial casts of BRSMG Cb 2335 are also known (NHMUK R1309/1310; TCD.47762a+b; BGS GSM 118410). Each comprises a representation of the skull, nine anterior cervical vertebrae including the atlas-axis, and the right forelimb.

Diagnosis. As for only known species.

Atychodracon megacephalus (Stutchbury, 1846)

$$
\text { Figures 1-7 }
$$

1846 Plesiosaurus megacephalus Stutchbury, p. 412-417, figs. 1-4.

1881 Plesiosaurus megacephalus Sollas, p. 472.

1889 Thaumatosaurus megacephalus Lydekker, p. 166.

1922 Eurycleidus megacephalus Andrews, p. 294-5, fig. a.
1930 Thaumatosaurus megacephalus Swinton, p. 341.

1948 Plesiosaurus megacephalus Swinton, p. 350-356, pl. 11.

1989 'Plesiosaurus' megacephalus Taylor and Cruickshank, p. 20-24.

1994 Plesiosaurus megacephalus Taylor, p. 189, fig. 5 .

1994a Rhomaleosaurus megacephalus Cruickshank, p. 250.

2007 Eurycleidus megacephalus Smith, p. 214, figs. $4.45,4.46$.

Revised diagnosis. Moderately sized plesiosaurian (approximately $5 \mathrm{~m}$ long) with the following characters: relatively large skull (skull:total length ratio $=0.16$ ), premaxillary rostrum length subequal to width, five premaxillary teeth, anteroposteriorly oriented channel anterior to external naris, palatine contacts internal naris, anteroposteriorly elongate and mediolaterally narrow anterior interpterygoid vacuity, gently keeled parabasisphenoid, mediolaterally bowed mandibular ramus, laterally expanded mandibular symphysial region with length subequal to width, diverging bars and a midline longitudinal crest on the ventral surface of the dentary adjacent to the mandibular symphysis, splenials contribute to mandibular symphysis and make contact on the ventral midline, narrow cleft on midline between the dentaries, large lingual mandibular foramen, medial boss on retroarticular process; 29-30 cervical vertebrae (including the atlas and axis) $\sim 32$ caudal vertebrae, anterior process on cervical ribs, straight preaxial humerus margin, radius and ulna facets on humerus poorly defined, humerus slightly shorter than femur, ulna shorter than radius, tibia and fibula equal length.

Occurrence. BRSMG Cb 2335 was from the lowermost beds of the Blue Lias Formation (Lower Lias, Hettangian) of Street-on-the-Fosse (Wright, 1860, p.391), a village about $14 \mathrm{~km}$ ENE of Street, Somerset, UK (Cruickshank, 1994a; Storrs and Taylor, 1996). Specimens in and around Street probably originate from the pre-Planorbis beds (below the first occurrence of Psiloceras planorbis), in the Psiloceras tilmanni Zone that immediately follows the Triassic-Jurassic boundary, however, it is possible that some specimens are from slightly younger deposits (Storrs and Taylor, 1996; Benson et al., 2012). Swinton $(1930,1948)$ wrongly gave the locality of BRSMG Cb 2335 as Street and ascribed the occurrence to the "?angulatum Zone" (upper Hettangian) (see discussion in Cruickshank 


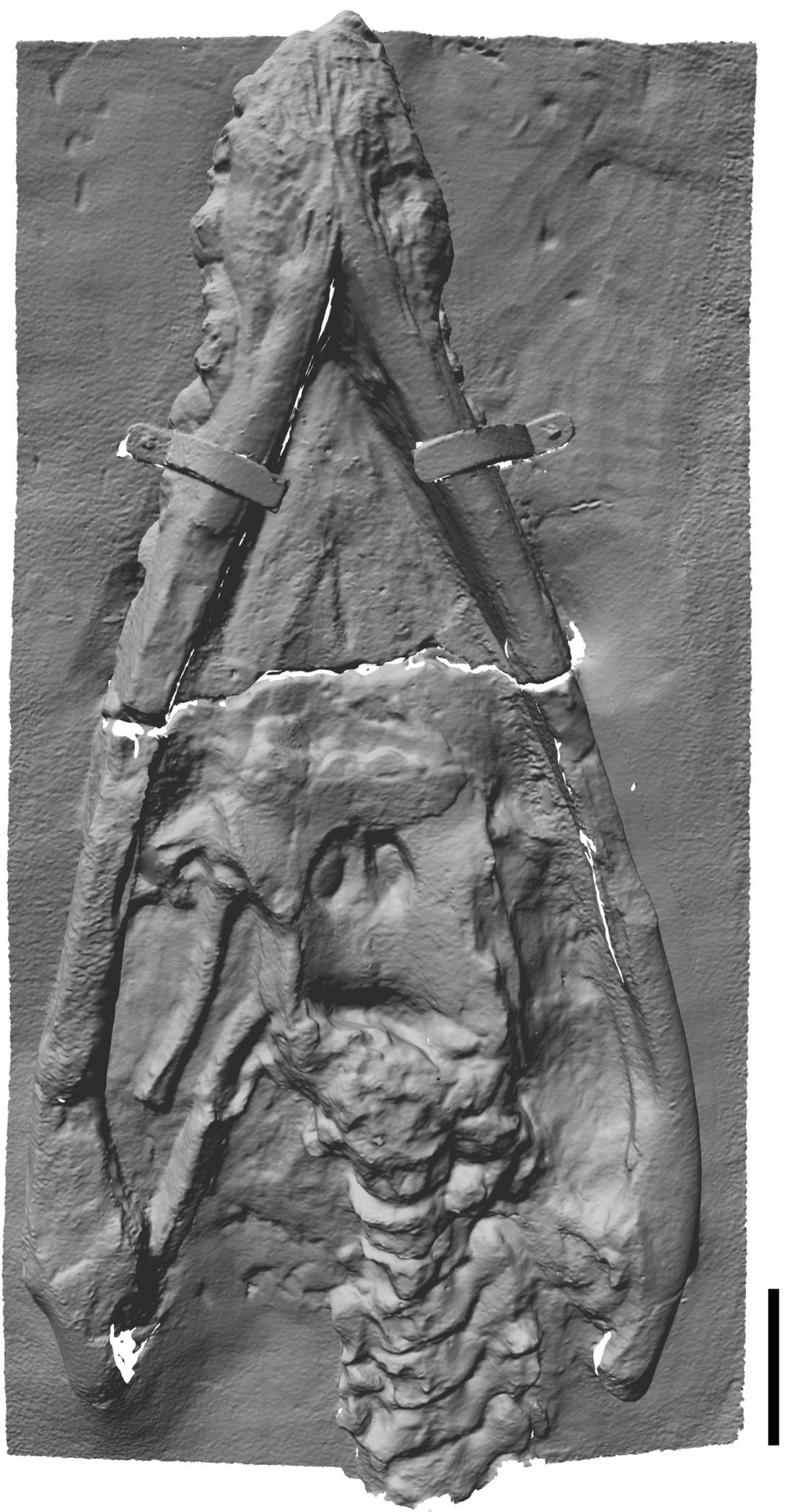

FIGURE 2. Plaster cast (BGS GSM 118410) of the holotype (BRSMG Cb 2335) skull of Atychodracon megacephalus (Stutchbury, 1846) in ventral (palatal) view. Three dimensional scan with texture (colour) removed. Scale bar equals $100 \mathrm{~mm}$. 
(1994a, p. 251) and Storrs and Taylor (1996, p. 405).

Referred specimens. The following specimens are referred to Atychodracon megacephalus pending a thorough evaluation of the material with reference to the holotype: LEICS G221.1851 (the neotype specimen) from Barrow-upon-Soar, Leicestershire, UK (Cruickshank, 1994a, 1994b); NMING F10194, a partial skeleton including the skull (but no mandible) from Street (Smith, 2007; Benson et al., 2012); NMING F8749, a partial skeleton including a damaged skull and suffering from pyrite decay, also from Barrow-upon-Soar (Smith, 2007). A complete skeleton from Wilmcote, Warwickshire, UK, sometimes referred to ' $P$.' megacephalus (WARMS G10875, Wright, 1860; Cruickshank, 1994a) represents a new species (Smith, 2007).

Remarks. The ICZN (International Commission on Zoological Nomenclature, 1999) regulates type specimens based on illustrations or descriptions (Article 72.5.6). Historical photographs of BRSMG Cb 2335 by Swinton (1948) and descriptions and illustrations by Stutchbury (1846), Sollas (1881), and Swinton (1948), allow for a satisfactory diagnosis of the taxon and fulfil the requirements set forth in ICZN Article 72.5.6 for eligibility as a namebearing type, where "the name bearing type is the specimen illustrated or described (and not the illustration or description itself)" (International Commission on Zoological Nomenclature, 1999, p. 78). ICZN article 72.5.3 recognises casts and moulds as eligible name bearing types only if they are "natural" (p. 77). There are no provisions in the ICZN for three-dimensional representations of types. However, the existing plaster casts of BRSMG Cb 2335 (and three-dimensional laser scans of these casts) provide valuable additional representations of the destroyed type material. 'P.' megacephalus is an available species name despite the loss of its type, and it is regarded here as the type species of the genus Atychodracon. Note also that the ICZN regulates type specimens for new species names but not type species for new higher taxa.

Cruickshank (1994a) described a neotype specimen for ' $P$.' megacephalus in the absence of the original holotype material (LEICS G221.1851, see Taylor and Cruickshank, 1989 and Cruickshank, 1994b for a history of the specimen). According to ICZN article 51.1, a neotype is designated when a name bearing type is considered necessary to define the taxon objectively (Article 75.8) (International Commission on Zoological Nomenclature, 1999). Since Atychodracon megacephalus can be defined objectively based on the representations of BRSMG Cb 2335 listed above, LEICS G221.1851 is regarded as a referred specimen of $A$. megacephalus that provides the opportunity for new observations on the taxon that cannot be made on the surviving representations of the type specimen.

\section{Comparative description}

Each painted plaster cast consists of the skull associated with the anterior cervical vertebrae, and right forelimb (Figures 2-7). In NHMUK R1309/ R1310 and BGS GSM 118410 the skull and limb are mounted on a single slab, whereas the skull and $\operatorname{limb}$ are preserved on separate slabs in TCD.47762a and TCD.47762b. The preorbital region of the skull can be completely detached from the slab as a three-dimensional representation of the rostrum (but note that the rostrum segment is presently stuck in NHMUK R1309/1310). The following anatomical description is based on BGS GSM 118410 unless stated otherwise, although no obvious differences were observed between any of the casts, except for superficial discrepancies in the paintwork. Bone surface details and sutures are generally clear, and for the sake of simplicity and clarity, the description is formatted as though the specimen is a real fossil (unless stated otherwise) with references to bones and matrix. Measurements are taken from BGS GSM 118410 and match those taken from the holotype by Swinton (1948). This indicates that the casts are a reliable representation of the original material and have not suffered from deformation. Some insignificant minor variation between the measurements of different authors can be attributed to variation in the manual process of measuring bones. This redescription is primarily restricted to that material represented by the casts, although it is augmented with (and compared to) data collected from the original material by previous authors (Stutchbury, 1846; Swinton, 1948; Sollas, 1881), where appropriate.

\section{Cranium}

Premaxilla. The 'premaxillary rostrum' (i.e., the portion of the premaxilla anterior to the mediolateral constriction) is expanded mediolaterally (Figure 3.1-3). The width of the premaxillary rostrum is equal to its anteroposterior length $(110 \mathrm{~mm})$ (length:width ratio $=1)$. This is similar to some species of Rhomaleosaurus ( $R$. zetlandicus ratio = $0.96 ; R$. thorntoni ratio $=0.98$ ) and Meyerasaurus $($ ratio $=1.07)$ (Smith, 2007; Smith and Benson, 

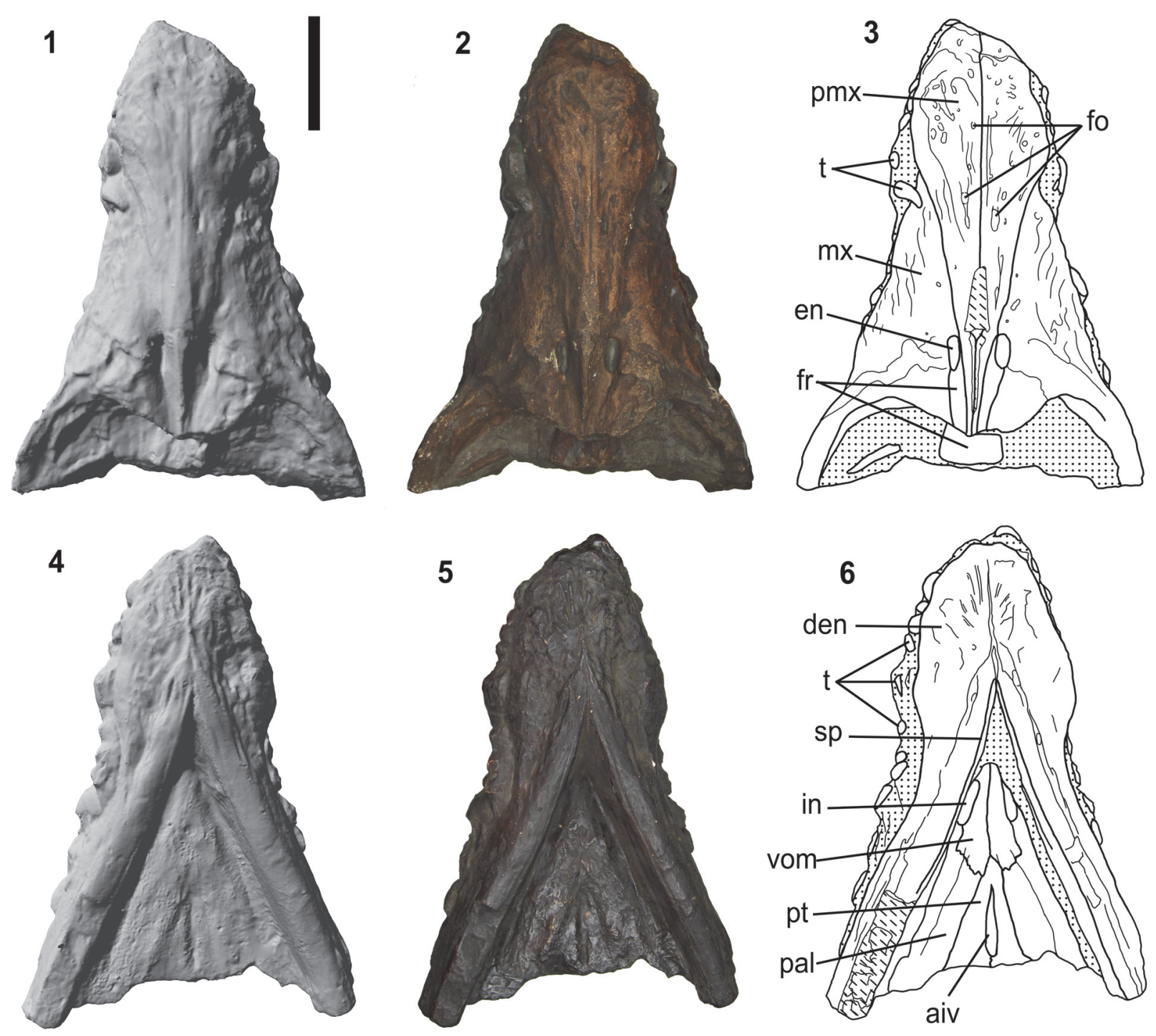

FIGURE 3. Plaster cast (BGS GSM 118410) of the anterior part of the holotype (BRSMG Cb 2335) skull of Atychodracon megacephalus (Stutchbury, 1846). 1-3, dorsal views, 4-6, ventral views. 1 and 4, three dimensional scans with texture (colour) removed, 2 and 5, photographs, 3 and 6, interpretations. Abbreviations: aiv - anterior interpterygoid vacuity; den - dentary; en - external naris; fo - nutritive foramina; fr - frontal; in - internal naris; $\mathbf{m x}$ maxilla; pal - palatine; pmx - premaxilla; pt - pterygoid; sp - splenial; $\mathbf{t}$ - teeth; vom - vomer. Cross-hatching represents original broken surfaces, stippling represents original matrix. Scale bar equals $100 \mathrm{~mm}$.

2014), but different to other specimens referred to Atychodracon megacephalus which have longer premaxillary rostra (LEICS G221.1851, ratio = 1.57; and NMING F10194, ratio = 1.55) (Smith, 2007). The premaxillae have a well-defined, straight midline contact along their preserved length. Randomly distributed foramina are present on the dorsolateral surface of the body of the premaxilla. A well-defined mediolateral constriction marks the contact of the premaxilla and maxilla, as in many pliosauromorph plesiosaurians, including Rhomaleosaurus (Taylor, 1992; Vincent and Smith, 2009). The premaxilla-maxilla contact extends posterodorsally along the dorsolateral surface of the snout and contacts the external naris (Figure 3.13 ). This condition is different to the anteroposteriorly parallel oriented maxilla-premaxilla sutures in Rhomaleosaurus (Smith and Dyke, 2008; Smith and Benson, 2014) and Maresaurus coccai (Gasparini, 1997, text-figure 1). The posterodorsal pro- 
1

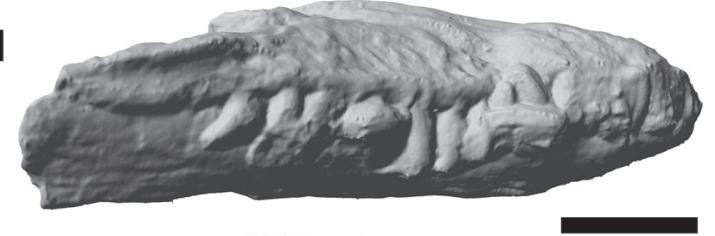

2

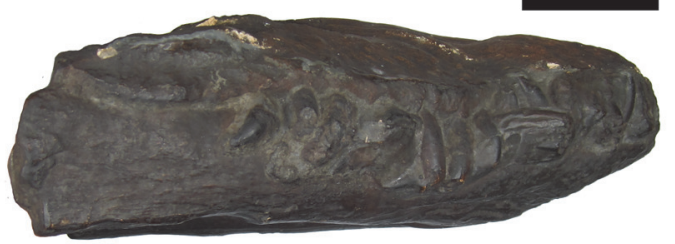

3

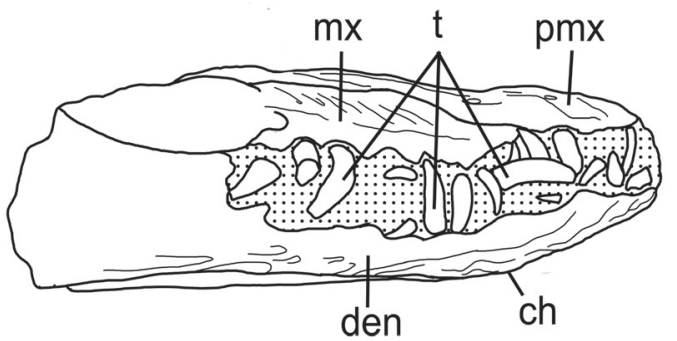

7

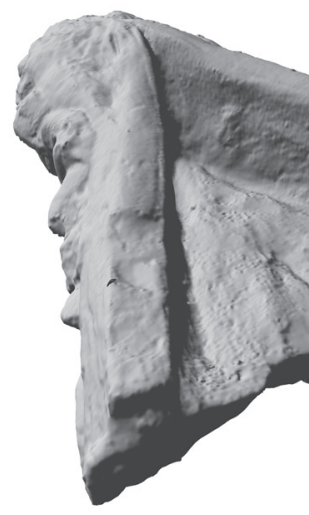

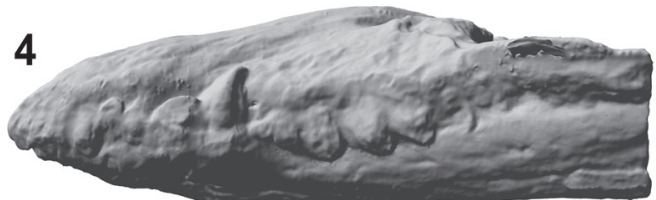
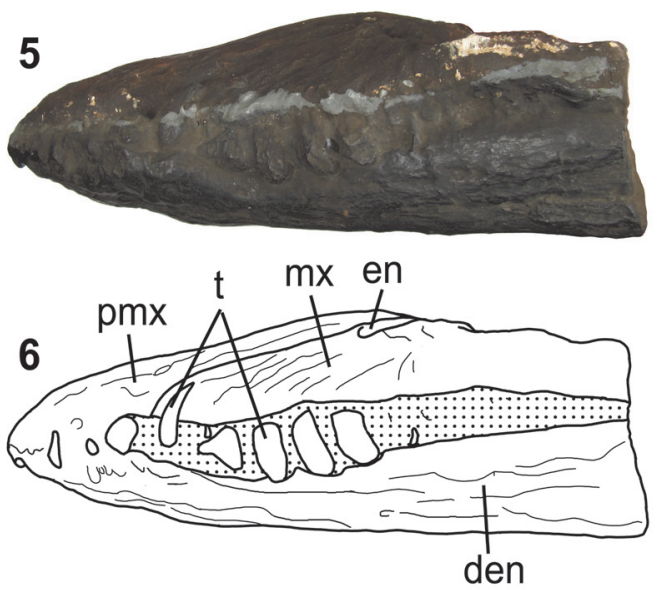

8

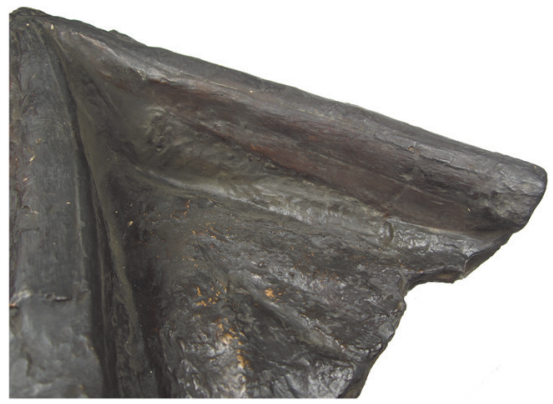

sp

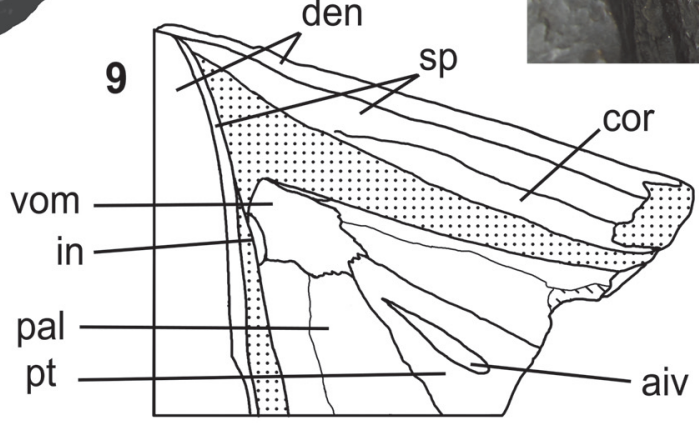

FIGURE 4. Plaster cast (BGS GSM 118410) of the anterior portion of the holotype (BRSMG Cb 2335) skull of Atychodracon megacephalus (Stutchbury, 1846). 1-3, right lateral view, 4-6, left lateral view, 7-9, oblique posterolateral view. 1, 4, 7, three dimensional scans with texture (colour) removed, 2, 5, 8, photographs, 3, 6, 9, interpretations. Abbreviations: aiv - anterior interpterygoid vacuity; ch - chin; cor - coronoid; den - dentary; en - external naris; in - internal naris; $\mathbf{m x}$ - maxilla; pal - palatine; pmx - premaxilla; $\mathbf{p t ~ - ~ p t e r y g o i d ; ~ s p ~ - ~ s p l e n i a l ; ~} \mathbf{t}$ - teeth; vom - vomer. Cross-hatching represents original broken surfaces, stippling represents original matrix. Scale bar equals $100 \mathrm{~mm}$.

cess of the premaxilla extends posteriorly past the external nares but this region is dorsoventrally compressed and the sutures are unclear. There is an anteroposteriorly oriented crest-like dorsomedial ridge along the median contact of the premaxillae between and posterior to the external nares (Figure 6.4). This is mediolaterally broad and rounded anterior to the external nares (Figure 6.3) (Sollas, 1881, figure 11), although this may have been enhanced by dorsoventral compression.

Maxilla. The maxilla is a large triangular bone that contacts the premaxilla medially along a long posteromedially directed suture and contributes to the anterior and lateral margin of the external naris and 
extends posteriorly below the orbit (Figures 3.1-3, 4.1-6). The external nares are relatively large (27.6 $\mathrm{mm}$ long and $11.2 \mathrm{~mm}$ wide) with steep lateral and medial walls (Figure 6.4). A shallow channel formed by the maxilla and bounded medially by the premaxilla extends anterolaterally from the external naris (Figure 6.3), so the anterior wall of the external naris, formed by the maxilla, is sunk relative to the lateral and medial walls. The maxilla has a sculptured rugose lateral surface (Figure 4.1-6). It is damaged posteriorly so its relationship to the frontals, prefrontals, and orbital opening is unclear, and the maxilla-jugal contact is not visible.

Frontals. The region of the skull anterior and medial to the orbits is dorsoventrally compressed (Figure 6.5), and the relationship and morphology of the bones is unclear in this region. The frontal appears to extend anteriorly as a mediolaterally narrow process that contacts the external naris (Figure 3.1-3).

Palate. Most of the ventral surface of the palate appears to be exposed but the sutures are poorly visible (Figures 2, 3.4-6, 4.7-9, 5). Sollas (1881) stated: "The matrix has been carefully chiseled away from between the rami of the lower jaw, so as to clearly expose the roof of the mouth." Sollas (1881, figures 8,9, p. 472) also provides figures and detailed descriptions (p. 472-473) of the palatal sutures and internal nares, but these sutures are not clearly visible in the casts. This suggests that the moulds of the skeleton were taken before the palate of the holotype was prepared. Sollas (1881) provides a relevant note where he reports that Seeley "had an impression that the palatal foramina [=internal nares]...were shown in the species described by Mr. Stutchbury fourteen years ago" [=1867], and that "he believed they [the internal nares] had been excavated after that description [presumably Stutchbury, 1846] had been drawn up" (p. 480). The preparation of the palate therefore probably happened between 1846 and 1867 , and certainly prior to 1881 (the date of publication of Sollas' paper). Swinton (1948) noted, based on observations he took of the material shortly before it was destroyed, that the palatal surface "is much damaged by cracks and by the addition of plaster" (p. 351), and added: "Since Sollas' examination of it, the intersymphysial part seems to have had plaster added" (p. 351). As such, he was also unable to verify the sutures around the internal nares as identified by Sollas. For this reason the palatal sutures in my interpretations (Figures 3.6, 4.9) are based only on Sollas' (1881) and should be regarded as tentative, especially given that the interpretative illustrations by Sollas are simplified and diagrammatic. This also means that it is possible the moulds were taken after Sollas described the specimen. BGS GSM 118410 was entered into the Geological Survey Museum register in 1888, and NHMUK R1309/1310 was entered into the museum register in 1888 , so the moulds were certainly taken prior to 1888 .

Vomer. The ventral surface of the palate in the region of the vomers is mediolaterally convex (Figure 6.3). According to Sollas (1881) the vomer forms the medial margin of the internal naris and extends posteriorly to contact the pterygoid (identified by Sollas (1881) as the palatine) and palatine along an interdigitating suture. My interpretation (Figure 3.6) is based directly on Sollas' observations, however, it isn't possible to verify the anatomy of this region on the basis on the casts. Cruickshank (1994a) interpreted the vomers in LEICS G221.1851 as terminating at the posterior margin of the nares, but reexamimation shows they extend posteriorly beyond them (Smith, 2007), as is also the case in NMING F10194, and most other rhomaleosaurids including Rhomaleosaurus (Taylor, 1992, Smith and Dyke, 2008; Smith and Benson, 2014) and Meyerasaurus (Smith and Vincent, 2010).

Pterygoid. The pterygoids are separated for c. 60 $\mathrm{mm}$ along the midline forming an anteroposteriorly broad and mediolaterally narrow anterior interpterygoid vacuity (Figures 3.4-6, 6.5). The posterior margin of this vacuity is clear and forms a tight curve, but its lateral and anterior margins are less clear. The posterior rami of the pterygoids extend below the braincase and contact each other on the midline posterior to the posterior interpterygoid vacuities (Figure 5). The ventral surface is strongly mediolaterally concave with a ventrolaterally directed lateral margin (Figure 6.7) that probably extended further posterior to underly the quadratepterygoid flange ("squared lappet" sensu O'Keefe, 2001).

Palatine. Sollas (1881) described and figured the palatine, which he interpreted as contributing to the posterior margin of the internal naris (Sollas, 1881, figure 9). This is also the case in all referred specimens of Atychodracon (NMING F10194, LEICS G221.1851; NMING F8749) but differs from Stratesaurus (Benson et al., in press), Meyerasaurus (Smith and Vincent, 2010) and Rhomaleosaurus (Taylor, 1992; Smith and Benson, 2014), in which the palatine is excluded from the margin of the internal naris. 
Ectopterygoid. Part of a possible ectopterygoid is exposed on the right side of the palate where it forms the curved anterior margin of the subtemporal fenestra (Figure 5).

Parabasisphenoid. The parabasisphenoid is gently keeled for its entire length between the posterior interpterygoid vacuities (Figure 6.6). The cultriform process on the palate appears to be short and triangular but the sutures are unclear (Figure 5). The sutures between the parasphenoid, basisphenoid, and pterygoid, are unclear in the cast, but Swinton (1948) described them in some detail and gave measurements for the elements. For example, the parasphenoid-basisphenoid suture "can be seen clearly to run from almost the posterior limit of the right post-palatine [posterior interpterygoid vacuity] to a point slightly in front of the posterior limit of the left" (p. 352). Swinton (1948) also described the pterygoid-basisphenoid sutures as "running straight backwards and starting just outside [lateral to] the ends of the [parasphenoid-basisphenoid suture]" (p. 352). I have therefore based my interpretation of this region on this description, where it isn't clear from the cast, and so it must be regarded as tentative. It is also possible that the element identified as the basisphenoid by Swinton (1948), is in fact the basioccipital, and that the parasphenoid and basisphenoid are fused.

\section{Mandible}

The mandibular rami are mediolaterally bowed (sensu Druckenmiller and Russell, 2008) (Figure 2): the left ramus is $830 \mathrm{~mm}$ long and the jaws are widest $(455 \mathrm{~mm})$ immediately anterior to the articular glenoid. The medial surface of the mandible is generally well preserved and longitudinally oriented contacts between elements can be traced for most of their length (Figure 4.7-9).

Dentary. The dentary forms most of the anterior part of the mandibular ramus including the conjoined mandibular symphysis ( $127.1 \mathrm{~mm}$ long). The region surrounding the mandibular symphysis is laterally expanded and 'spatulate', as is common in pliosauroids (O'Keefe, 2001) (Figure 3.4-6). The region of the mandibular symphysis is widest posteriorly (128.5 $\mathrm{mm}$ wide) and therefore tapers anteromedially for most of its length. The length: width ratio of the mandibular symphysis region is almost equal (ratio $=1.01$ ). This is similar to LEICS G221.1851 (ratio $=1.09$ ) and Eurycleidus (ratio = 0.98 , Smith, 2007) but different to Rhomaleosaurus, which has a proportionally shorter mandibular symphysis (ratio $=0.73-0.86$; Smith, 2007), and Macroplata, which has a proportionally longer man- dibular symphysis (ratio $=1.36$ ) (Ketchum and Smith, 2010). The length of the mandibular symphysis relative to the length of the mandibular ramus is 0.16 , similar to LEICS G221.1851 (ratio = 0.14 ) and Rhomaleosaurus (ratio $=0.12$ ). The ventral surface of the symphysis bears a mediolaterally narrow, shallow, longitudinal crest on the midline (Figures 3.4-6, 6.2), as is present in other rhomaleosaurids, including Rhomaleosaurus (Taylor, 1992), Meyerasaurus (Smith and Vincent, 2010), and Eurycleidus (NHMUK R2030* pers obs.). In Atychodracon, this crest bifurcates posteriorly and becomes separated by a midline cleft that is bordered by the splenials posteriorly (Figure 3.4-6). A cleft is also present but does not contact the splenials in Eurycleidus (NHMUK R2030*, pers obs.). A series of anteriorly and anterolaterally oriented ridges, separated by shallow troughs, radiate from the midline on the ventral surface of the mandibular symphysis (Figure 3.4-6). Cruickshank (1994a) described similar "diverging bars of bone" (p. 256) on the underside of the symphysis in LEICS G221.1851, but these ridges are absent in Rhomaleosaurus (Taylor, 1992). In lateral view the dentary forms a distinct 'chin' where the sloping symphysial region meets the postsymphysial ramus (Figure 4.1-6). The posterior part of the mandibular symphysis forms a triangular fossa, equivalent to the 'post-symphysial vacuity' described by Gomez-Perez (2004), flanked laterally by the medial walls of the splenials. Distinct anteroposteriorly oriented elongate troughs on the ventral surface of the dentaries are situated adjacent to the end of the symphysis, one on the left, two on the right (Figure 3.4-6). Each of these contains a nutritive foramen, as in Eurycleidus (NHMUK R2030*, pers obs.), which has paired foramina in this region. Posterior to the mandibular symphysis the mandibular ramus becomes mediolaterally compressed (Figure 6.5-7).

Splenial. The splenial is an anteroposteriorly elongate splint-like element in plesiosaurians. In Atychodracon the splenial is visible on the medial surface of the mandibular ramus, contacting the dentary ventrolaterally and the coronoid dorsally, with extensive contacts that run parallel to the dorsal and ventral margins of the ramus (Figure 4.79 ). The splenials terminate anteriorly with pointed tips that form the posterior margin of the midline cleft. They participate to the mandibular symphysis and make contact along the ventral midline for a short distance anteriorly, as in most other pliosauroids and rhomaleosaurids (Smith and Dyke, 2008; Smith and Vincent, 2010). In Eurycleidus (NHMUK 
1

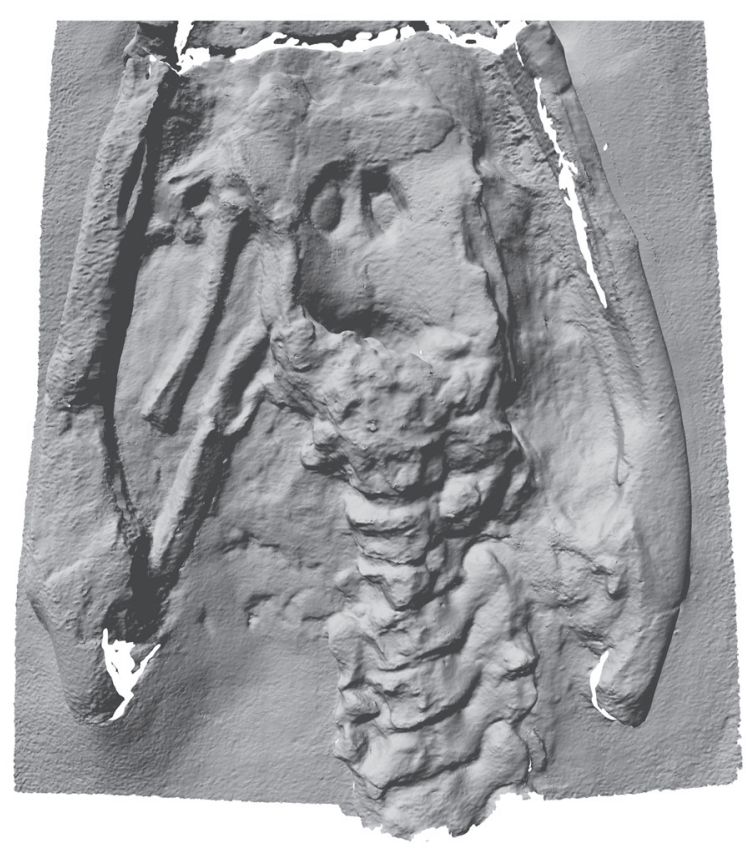

2

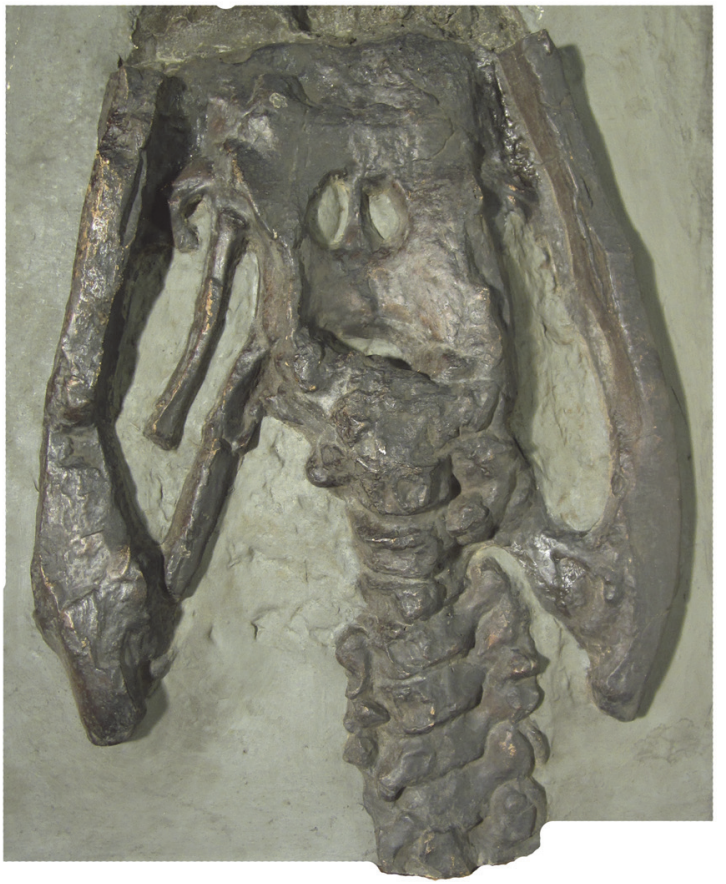

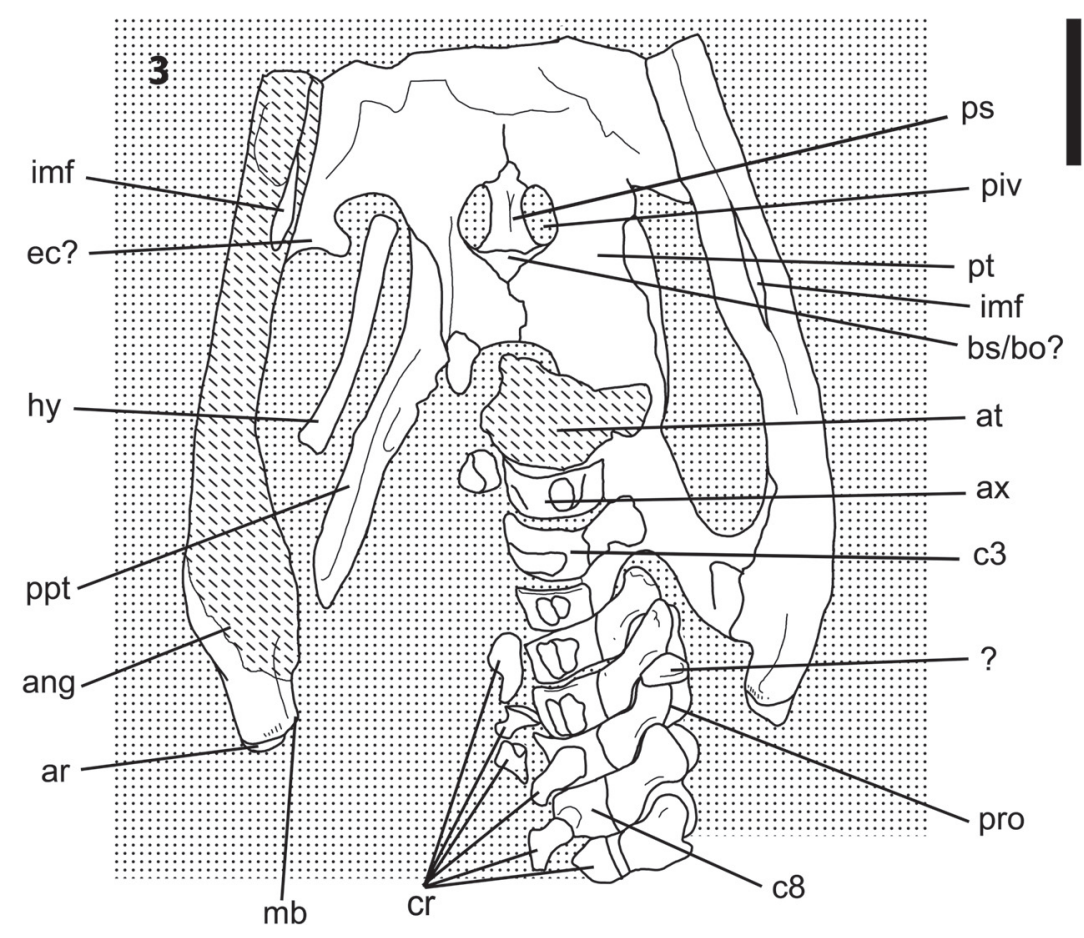

FIGURE 5. Posterior part of a plaster cast (BGS GSM 118410) of the holotype (BRSMG Cb 2335) skull of Atychodracon megacephalus (Stutchbury, 1846) in ventral (palatal) view. 1, three dimensional scan with texture (colour) removed, 2, photograph, 3, interpretation. Abbreviations: ang - angular; ar - articular; at - atlas; ax - axis; bs/bo? - basisphenoid or basioccipital; c3 - cervical vertebra 3; c8 - cervical vertebra 8; cr - cervical ribs; ec? - probable ectopterygoid; hy - hyoid; imf - internal mandibular foramen; $\mathbf{m b}$ - medial boss of retroarticular process; piv - posterior interpterygoid vacuity; ppt - posterior process of pterygoid; pro - possible additional process between zygapophyses; ps - parasphenoid; pt - pterygoid; ? - unknown element. Cross-hatching represents original broken surfaces, stippling represents original matrix. Scale bar equals $100 \mathrm{~mm}$. 

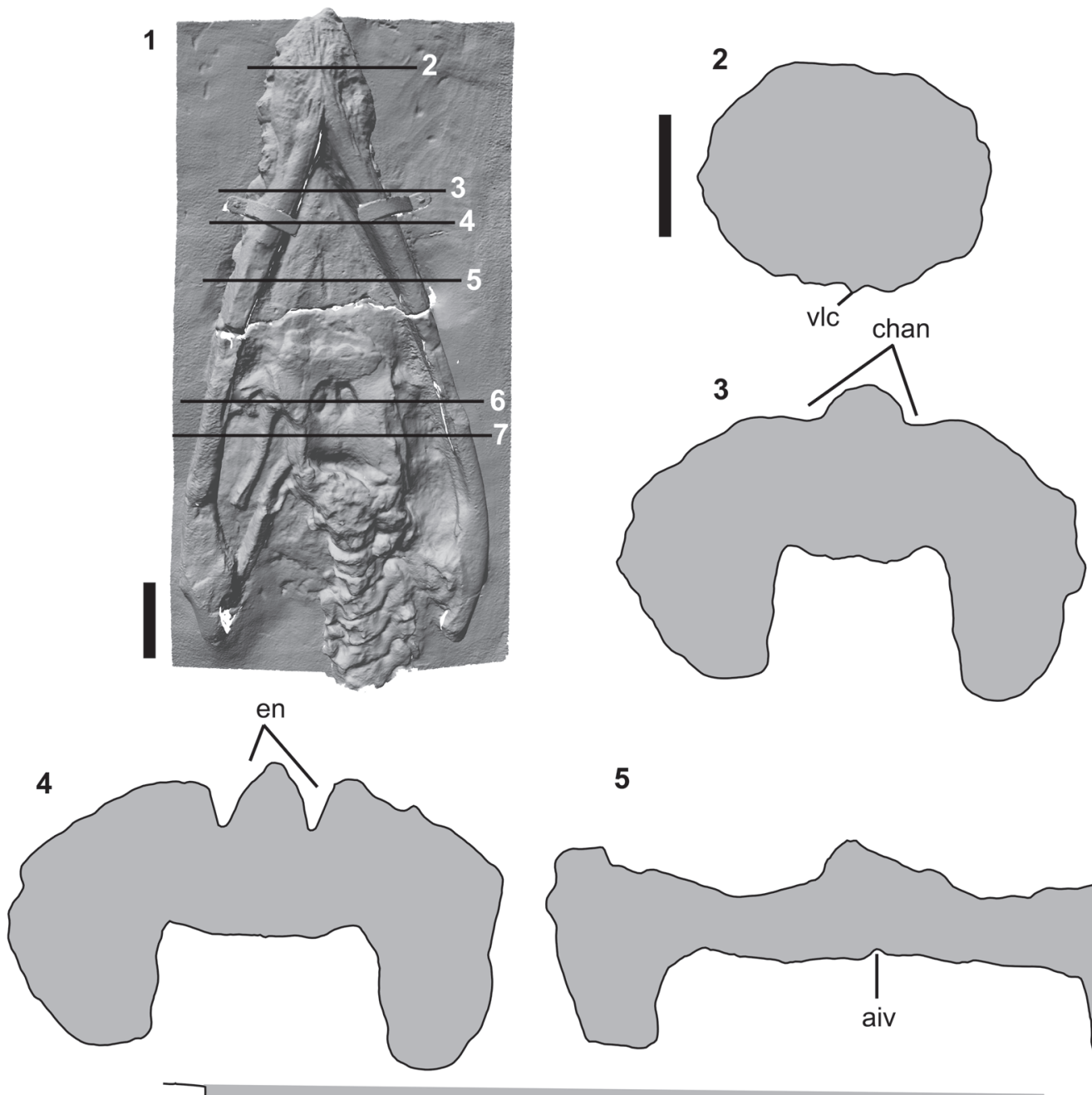

5

6
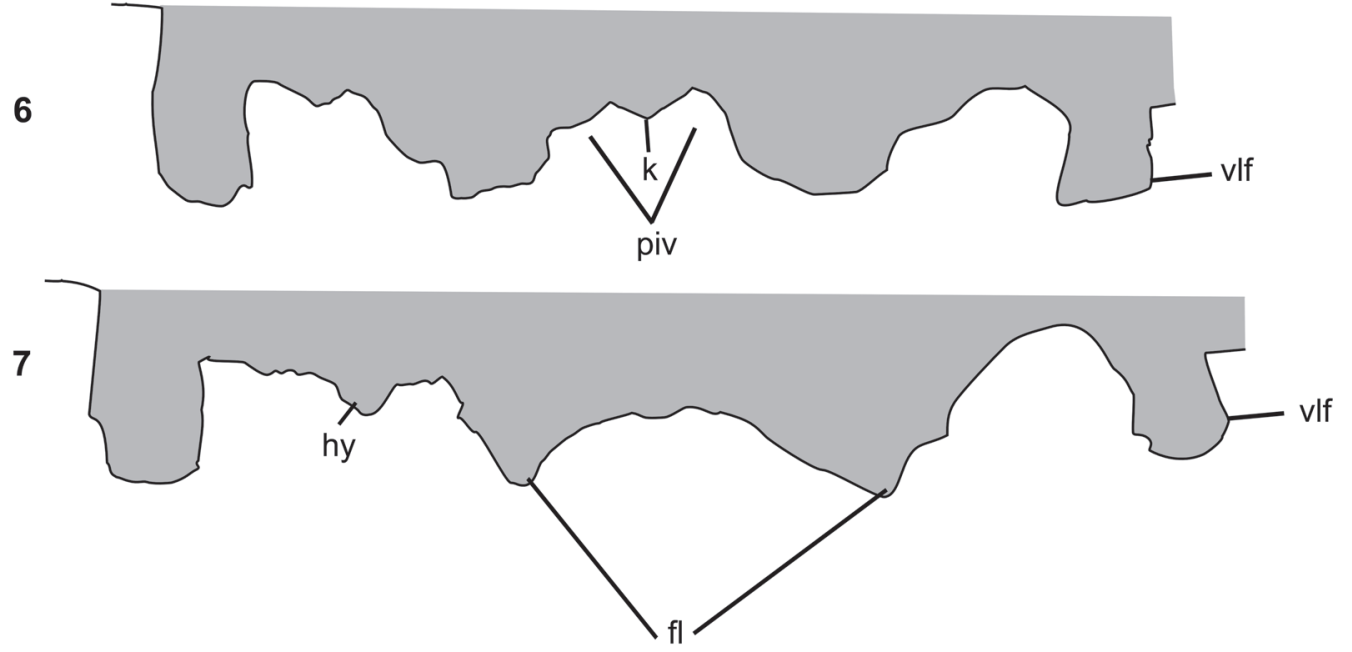

FIGURE 6. Transverse cross-sections of the plaster cast (BGS GSM 118410) of the holotype (BRSMG Cb 2335) skull of Atychodracon megacephalus (Stutchbury, 1846), showing surface morphology. 1, ventral view of skull showing position of cross-sections, 2-7, cross-sections, dorsal surface towards top. Abbreviations: aiv - anterior interpterygoid vacuity; chan - channels anterior to external nares; $\mathbf{f l}$ - ventrolaterally directed flanges of pterygoid; hy - hyoid; en - external nares; $\mathbf{k}$ - ventral keel on parasphenoid; piv - posterior interpterygoid vacuity; vic - ventral longitudinal crest; vlf - ventrolateral flange. Scale bar equals $100 \mathrm{~mm}$ (in 1) and $50 \mathrm{~mm}$ (in 2-7), note that cross-sections are to scale relative to each other. 
R2030*, pers. obs.) the morphology is different because although the splenials extend anteriorly beyond the posterior end of the mandibular symphysis, they are separated from each other along the midline by a small asymmetrical vacuity. Anteriorly the splenial-coronoid contact appears to become broadly sinuous but its anteriormost extent is not visible. The posterior part of the mandible is difficult to interpret but the splenial probably extended posteriorly to contact the lingual medial foramen (Figure 5).

Coronoid. The coronoid is an elongate splint-like bone on the dorsal part of the medial surface of the mandible (Figure 4.7-9). It is bordered by the splenial ventrally, but the dorsomedial and anterior surface of the coronoid is obscured by the palate and 'matrix'.

Angular. The anatomy of the posterior part of the mandible is unclear and most of the right ramus is damaged (Figure 5). The ventral surface of the ramus is formed almost entirely by the angular, which is expanded below the mandibular glenoid (87 $\mathrm{mm}$ wide on the right ramus, $70 \mathrm{~mm}$ wide on the left ramus) and extends posterior to the glenoid to form the ventral surface of the retroarticular process (Figure 5). The expansion below the glenoid is almost entirely medial, while the expansion on the lateral surface is weak. The angular bears longitudinal striations on its lateral surface that extend along the mandible, and the ventrolateral surface is expanded into a ventrolateral flange or buttress (Figure 6.6-7), as in Rhomaleosaurus (Smith and Benson, 2014). There is a large internal mandibular foramen (=lingual mandibular fenestra, O'Keefe, 2001) on the ventromedial surface of the mandible, approximately level with the posterior interpterygoid vacuities. An opening has also been described in this position in Meyerasaurus (Smith and Vincent, 2010) and Rhomaleosaurus (Taylor, 1992), and a small foramen present in Peloneustes (Ketchum and Benson, 2011), Pliosaurus (Benson et al., 2013a), and Stratesaurus (Benson et al., in press) may also be homologous. There is a transverse band of longitudinally oriented rugosities on the ventral surface of the retroarticular process indicating the position of the angular-articular suture. The distal end of the retroarticular process is divided into two equally sized faces, one facing posteriorly, the other facing posteromedially. The latter is expanded slightly medially into a rounded medial boss (Figure 5), as in NMING F8749 (Smith, 2007).

Articular. The posterior part of the articular extends posteriorly beyond the angular and forms the terminal portion of the retroarticular process. This is also the case in Rhomaleosaurus (Taylor, 1992). The articular is otherwise not visible.

Hyoid. A splint-like right hyoid bone is preserved in approximate life position in the right subtemporal fenestra (Figures 2, 5). It is "almost if not actually complete" (Swinton, 1948, p. 352) and measures $147 \mathrm{~mm}$ along its long axis. It is slightly expanded at each end, $24 \mathrm{~mm}$ wide anteriorly, $23 \mathrm{~mm}$ wide posteriorly, and a minimum $16 \mathrm{~mm}$ wide midshaft. The left hyoid was incomplete and obscured by matrix according to Swinton (1948), though its position is unclear in the cast.

Dentition. About 28 complete and partial teeth are preserved in situ, or nearly in situ, in the preorbital region of the skull. This is far fewer than "more than 60 " described by Stutchbury (1846, p. 412) and indicates that the resolution of the cast is lacking in this region. The surfaces of the teeth, as preserved, are smooth and unornamented. Stutchbury's (1846) description confirms that some teeth are smooth, although others are not: "[the teeth] are finely striated to towards their apex in the young state, but perfectly smooth in the matured teeth" (p. 412). The smooth condition is almost certainly an artefact of preservation because all rhomaleosaurids have apicobasally oriented striations in the mature state (Smith and Dyke, 2008). The lack of visible striations on any teeth in the cast must therefore be an artefact or limitation of the casting procedure. The lateral margin of the dentary adjacent to the mandibular symphysis is wavy, being slightly expanded in the presumed positions of alveoli, and indicates five tooth positions adjacent to the mandibular symphysis. Accordingly, there are probably five teeth in the premaxilla.

\section{Axial Skeleton}

There are nine vertebrae preserved in the cast including the atlas-axis complex and seven successive articulated postaxial cervical vertebrae (Figures 2, 5). This sequence, including intervertebral spaces, is $320 \mathrm{~mm}$ long. The vertebrae are all exposed in left lateral view but the neural spines are not visible.

Atlas-axis. The atlas-axis is highly abraded and little can be said of its morphology except to note its large size (98 $\mathrm{mm}$ long). The axis is preserved in conjunction with the atlas and bears a facet on its lateral surface, $21 \mathrm{~mm}$ high and $22 \mathrm{~mm}$ wide, for articulation with the axis rib. An indeterminate small bone situated ventral to the atlas-axis may be the axis rib. 
1

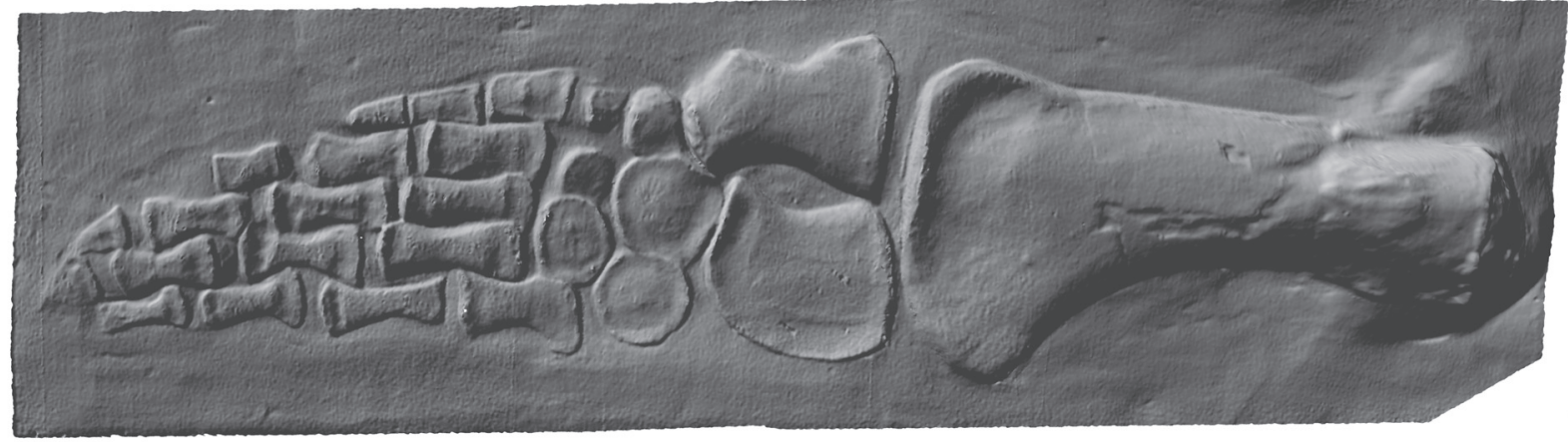

2

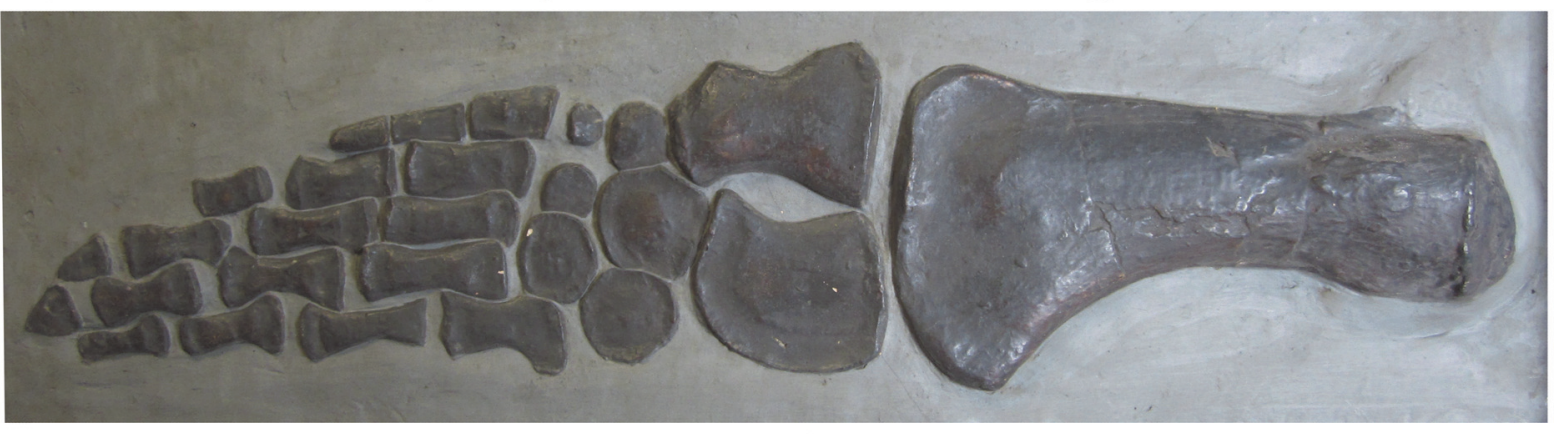

3

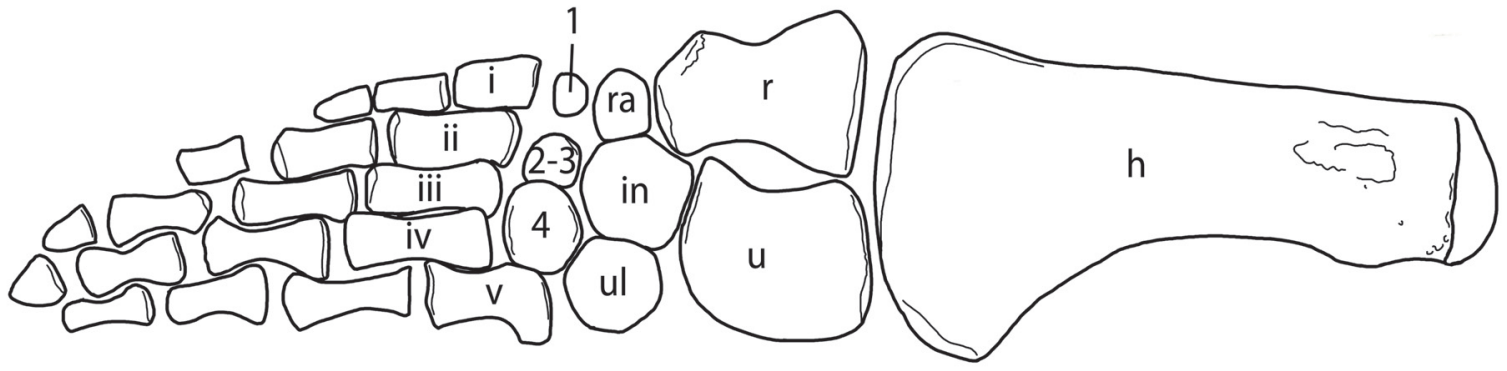

FIGURE 7. Plaster cast (BGS GSM 118410) of the ventral surface of the right forelimb of the holotype of Atychodracon megacephalus (Stutchbury, 1846) (BRSMG Cb 2335). 1, three dimensional scan with texture (colour) removed, 2 , photograph, 3, interpretation. Abbreviations: 1 - distal carpal 1; 2-3 - fused distal carpals 2 and 3; 4 - distal carpal 4; h - humerus; i - metacarpal i; ii - metacarpal ii; iii - metacarpal iii; iv - metacarpal iv; $\mathbf{v}$ - metacarpal v; in - intermedium; $\mathbf{r}$ - radius; radiale; $\mathbf{r a}$ - radiale; $\mathbf{u}$ - ulna; $\mathbf{u l}$ - ulnare. Scale bar equals $100 \mathrm{~mm}$.

Cervical vertebrae. The lateral surface of each anterior cervical vertebra is smooth and bears an oval facet for the cervical rib that occupies the lower two thirds and extends the whole length of the centrum (Figure 5). This facet has raised rims and is divided into subequal upper and lower facets separated by a narrow horizontal bar of bone. The neurocentral suture is horizontal to gently dorsally concave, but not strongly ' $V$ ' shape as in Rhomaleosaurus (Smith and Benson, 2014). The ventral surface of the centra is obscured but a ventral medial ridge was present (Swinton, 1948). The neural arch is dorsoventrally tall ( $59 \mathrm{~mm}$ in vertebra eight), roughly equivalent to the height of the cen- trum. The zygapophyses are positioned dorsally and appear to be articulated. The prezygapophyses are large oval processes that extend far anteriorly over the centrum body of the preceding vertebra. An unidentified element overlies the prezygapophyses in vertebra seven and may be a cervical rib. Swinton (1948) provided measurements of the entire cervical series.

Cervical ribs. Six cervical ribs are visible in the cast. The cervical ribs are short and robust with dorsoventrally tall proximal ends and dorsoventrally compressed distal ends. The distal end is expanded anteroposteriorly and bears a short anterior process and long posterior process (Figure 
5). The cervical ribs are preserved in situ in vertebra seven and eight.

\section{Appendicular Skeleton}

Forelimb. The entire right forelimb, with the exception of some partial and missing distal phalanges, is exposed in ventral view (Figure 7). It is $825 \mathrm{~mm}$ long from the proximal end of the humerus to the most distal phalange.

Humerus. The right humerus is complete. The shaft is $350 \mathrm{~mm}$ long, the humeral head is $93 \mathrm{~mm}$ wide, and the maximum distal width from the preaxial to postaxial margin is $183 \mathrm{~mm}$. These measurements closely match those given by Swinton (1948) (Table 1). The shaft has an almost straight preaxial margin and a strongly concave postaxial margin, so the humerus is expanded (or flared) distally (Figure 7). The straight preaxial margin is different to the condition in Eurycleidus, in which the distal preaxial expansion is more pronounced and the entire preaxial margin is more concave (NHMUK R2030*, pers obs.). The humerus is also more robust in Atychodracon compared to the more slender morphology present in Eurycleidus. A shallow eminence, the deltopectoral crest, is situated on the postaxial (posterior) surface close to the humeral head. The distal margin is weakly convex and the facets for the radius and ulna are unseparated and poorly defined.

Radius. The radius is a subrectangular element with a deeply concave preaxial and postaxial margin, and anteroposteriorly (pre-postaxially) expanded distal and proximal ends with flat articular surfaces (Figure 7). The radius is longer proximodistally $(117 \mathrm{~mm})$ than it is wide, and the proximal end is wider $(91 \mathrm{~mm})$ than the distal end $(69 \mathrm{~mm})$. This is similar to the condition in Eurycleidus, but differs from Rhomaleosaurus, where the width of the distal and proximal ends of the radius is subequal (Smith, 2007, $R$. cramptoni, figure 4.7; $R$. zetlandicus, figure 4.25). The preaxial margin forms an expanded flange on its proximal end with a distinct anteromedially facing facet separated from the humeral facet by a sharp angle. However, no additional preaxial elements are preserved in this region. The preaxial margin is more concave than the postaxial margin. The concave postaxial edge of the radius forms the anterior margin of a proximodistally broad, anteroposteriorly narrow, oval epipodial foramen (spatium interosseum), as is typical in Jurassic plesiosaurians. This foramen is bordered postaxially by the ulna and distally by the intermedium, which has a short contribution to the foramen between the radius and ulna.
Ulna. The ulna is a lunate element with a concave preaxial margin and convex postaxial margin, as is typical for Lower Jurassic plesiosaurians (Figure 7). It is $110 \mathrm{~mm}$ long and therefore slightly shorter than the radius. This contrasts with the condition in Eurycleidus, where the ulna is slightly longer than the radius (Smith, 2007). The ulna is $81 \mathrm{~mm}$ wide (anteroposteriorly) at midlength. The proximal surface is a flat facet for articulation with the humerus, the distal surface is divided into two flat facets, one for articulation with the intermedium, one for the ulnare. The anterodistal portion is pointed.

Carpals. Six subcircular carpals are arranged in two rows (Figure 7). The proximal row consists, from the preaxial to the postaxial margin of the limb, of the radiale, intermedium, and ulnare. The radiale is the smallest element $(31.8 \mathrm{~mm}$ proximodistally, $36.9 \mathrm{~mm}$ pre-postaxially) in the proximal row and contacts the radius proximally and intermedium postaxially. The circular intermedium is the largest carpal $(60.8 \mathrm{~mm}$ proximodistally, $59.1 \mathrm{~mm}$ pre-postaxially), and has a long flat proximal contact with the distal facet of the ulna, and a short contact with the radius. The ulnare is a circular disc $(54.5 \mathrm{~mm}$ proximodistally, $51.6 \mathrm{~mm}$ pre-postaxially), slightly smaller in size than the intermedium, which it contacts and overlaps slightly (as preserved). The ulnare also contacts distal carpal iv but not the ulna. The distal row of carpals consists of distal carpal i, fused distal carpal ii-iii, and distal carpal iv. The preaxial element (distal carpal i) is the smallest and the postaxial element (distal carpal iv) is the largest (43.8 $\mathrm{mm}$ proximodistally, 50.3 $\mathrm{mm}$ pre-postaxially). Distal carpal $i$ is a tiny subrectangular bone that does not contact any surrounding elements. Fused distal carpal ii-iii is a slightly larger circular disc that contacts the intermedium and distal carpal iv. Distal carpal iv is a large subcircular disc, that directly contacts several of its surrounding elements: the ulnare, fused distal carpal ii-iii, and metacarpal v). As preserved, distal carpal iv slightly overlaps the postaxial end of fused distal carpal ii-iii.

Metacarpals. There are five metacarpals with subrectangular or weakly hour-glass outlines (Figure 7). The first four metacarpals are arranged in a staggered row with the more postaxially positioned elements located more distally. Each overlaps its adjacent (preaxial) element slightly. In contrast, metacarpal $v$ is shifted proximally relative to the rest of the metacarpal row so that its proximal end is situated in the distal carpal row. Metacarpal $\mathrm{i}$ is the shortest in the row (47.3 $\mathrm{mm}$ long), its distal end terminates midway along the length of meta- 
TABLE 1. Selected measurements (in $\mathrm{mm}$ ) and vertebral counts for BRSMG Cb 2335 as given by Stutchbury (1846, measurements converted from inches), Sollas (1881, measurements converted from inches) and Swinton (1948), and measurements of BGS GSM 118410 for comparison.

\begin{tabular}{|c|c|c|c|c|}
\hline Measurement & $\begin{array}{l}\text { Stutchbury } \\
(1846)\end{array}$ & $\begin{array}{l}\text { Sollas } \\
(1881)\end{array}$ & $\begin{array}{c}\text { Swinton } \\
\text { (1948) }\end{array}$ & $\begin{array}{l}\text { BGS GSM } \\
118410\end{array}$ \\
\hline Total length & 4953 & 4953 & 4960 & $\mathrm{n} / \mathrm{a}$ \\
\hline Neck length & $\mathrm{n} / \mathrm{a}$ & 1430 & $\begin{array}{l}1350 / 1370 \text { (two conflicting } \\
\text { measurements are given) }\end{array}$ & $\mathrm{n} / \mathrm{a}$ \\
\hline Cervical vertebrae count & 29 & $29-30$ & 30 & $\mathrm{n} / \mathrm{a}$ \\
\hline Tail length & $\mathrm{n} / \mathrm{a}$ & 1384 & 1300 & $\mathrm{n} / \mathrm{a}$ \\
\hline Caudal vertebrae count & 31 & $\mathrm{n} / \mathrm{a}$ & 32 & $\mathrm{n} / \mathrm{a}$ \\
\hline Skull length (from anterior tip of snout to the...) & $\begin{array}{c}813 \text { (... end of the } \\
\text { articular bones })\end{array}$ & $\begin{array}{l}762 \text { (...back of } \\
\text { the quadrate) }\end{array}$ & 830 (...back of the angular) & $\begin{array}{c}830 \text { (...back of } \\
\text { the angular) }\end{array}$ \\
\hline Premaxilla tip to external nares length & 244 & $\mathrm{n} / \mathrm{a}$ & $\mathrm{n} / \mathrm{a}$ & 235 \\
\hline Premaxilla tip to orbit anterior margin length & 292 & $\mathrm{n} / \mathrm{a}$ & $\mathrm{n} / \mathrm{a}$ & 290 \\
\hline Premaxillary rostrum length & $\mathrm{n} / \mathrm{a}$ & $\mathrm{n} / \mathrm{a}$ & $\mathrm{n} / \mathrm{a}$ & 110 \\
\hline Premaxillary rostrum width & 133 & $\mathrm{n} / \mathrm{a}$ & $\mathrm{n} / \mathrm{a}$ & 110 \\
\hline External naris length & 28 & $\mathrm{n} / \mathrm{a}$ & $\mathrm{n} / \mathrm{a}$ & 27.6 \\
\hline External naris width & 12.7 & $\mathrm{n} / \mathrm{a}$ & $\mathrm{n} / \mathrm{a}$ & 11.2 \\
\hline Anterior interpterygoid vacuity length & $\mathrm{n} / \mathrm{a}$ & $\mathrm{n} / \mathrm{a}$ & $\mathrm{n} / \mathrm{a}$ & approx. 60 \\
\hline Mandibular symphysis length & 142 & $\mathrm{n} / \mathrm{a}$ & 150 & 127.1 \\
\hline $\begin{array}{l}\text { Maximum width of mandible adjacent to } \\
\text { mandibular symphysis }\end{array}$ & $\mathrm{n} / \mathrm{a}$ & $\mathrm{n} / \mathrm{a}$ & $\mathrm{n} / \mathrm{a}$ & 128.5 \\
\hline Maximum skull width (across mandible) & $\mathrm{n} / \mathrm{a}$ & $\mathrm{n} / \mathrm{a}$ & $\mathrm{n} / \mathrm{a}$ & 455 \\
\hline Skull width across angulars & $\mathrm{n} / \mathrm{a}$ & $\mathrm{n} / \mathrm{a}$ & 340 & 340 \\
\hline Length of premaxilla to basisphenoid & $\mathrm{n} / \mathrm{a}$ & $\mathrm{n} / \mathrm{a}$ & 570 & $\mathrm{n} / \mathrm{a}$ \\
\hline $\begin{array}{l}\text { Length of parasphenoid bar between posterior } \\
\text { interpterygoid vacuities }\end{array}$ & $\mathrm{n} / \mathrm{a}$ & $\mathrm{n} / \mathrm{a}$ & 48 & $\mathrm{n} / \mathrm{a}$ \\
\hline Posterior interpterygoid vacuity length & $\mathrm{n} / \mathrm{a}$ & $\mathrm{n} / \mathrm{a}$ & 46 & 42 \\
\hline Posterior interpterygoid vacuity width & $\mathrm{n} / \mathrm{a}$ & $\mathrm{n} / \mathrm{a}$ & 25 & 24 \\
\hline $\begin{array}{l}\text { Maximum width between the outer borders of the } \\
\text { posterior interpterygoid vacuities }\end{array}$ & $\mathrm{n} / \mathrm{a}$ & $\mathrm{n} / \mathrm{a}$ & 68 & 62 \\
\hline Preserved basisphenoid length & $\mathrm{n} / \mathrm{a}$ & $\mathrm{n} / \mathrm{a}$ & 36 & $\mathrm{n} / \mathrm{a}$ \\
\hline Width of mandibular ramus at glenoid & $\mathrm{n} / \mathrm{a}$ & $\mathrm{n} / \mathrm{a}$ & $\mathrm{n} / \mathrm{a}$ & $\begin{array}{c}70 \text { (left), } 87 \\
\text { (right) }\end{array}$ \\
\hline Maximum width of retroarticular process & $\mathrm{n} / \mathrm{a}$ & $\mathrm{n} / \mathrm{a}$ & $\mathrm{n} / \mathrm{a}$ & 39 \\
\hline Hyoid length & 145 & $\mathrm{n} / \mathrm{a}$ & 147 & 147 \\
\hline Atlas-axis length & $\mathrm{n} / \mathrm{a}$ & $\mathrm{n} / \mathrm{a}$ & $\mathrm{n} / \mathrm{a}$ & 98 \\
\hline Entire forelimb length & $\mathrm{n} / \mathrm{a}$ & 838 & $\mathrm{n} / \mathrm{a}$ & 825 \\
\hline Humerus length & 348 & 348 & 350 & 350 \\
\hline Humerus distal width & 178 & $\mathrm{n} / \mathrm{a}$ & 180 & 183 \\
\hline Width of humeral head & 84 & $\mathrm{n} / \mathrm{a}$ & 85 & 93 \\
\hline Radius length & 117 & 117 & 113 & 117 \\
\hline Proximal width of radius & 89 & $\mathrm{n} / \mathrm{a}$ & 91 & 91 \\
\hline Distal width of radius & 69 & $\mathrm{n} / \mathrm{a}$ & 70 & 69 \\
\hline Ulna length & 109 & 109 & 105 & 110 \\
\hline Width of the ulna at midlength & 84 & $\mathrm{n} / \mathrm{a}$ & 84 & 81 \\
\hline Femur length & $\mathrm{n} / \mathrm{a}$ & 343 & 340 & $\mathrm{n} / \mathrm{a}$ \\
\hline Tibia length & 114 & 114 & 118 & $\mathrm{n} / \mathrm{a}$ \\
\hline Fibula length & 114 & 114 & 118 & $\mathrm{n} / \mathrm{a}$ \\
\hline
\end{tabular}


carpal ii. All of the metacarpals have flat proximal and distal articular faces except for metacarpal iii, which has a proximal end divided into two flat articulations that face fused distal carpal ii-iii and distal carpal iv respectively. Metacarpal $\mathrm{v}$ is $67.2 \mathrm{~mm}$ long and the posterior surface of metacarpal $v$ is strongly convex, with a squared-off flange on the proximal posterior end. It is therefore more broad proximally $(41.5 \mathrm{~mm})$ than distally $(36 \mathrm{~mm})$.

Phalanges. 13 phalanges are preserved in total and the phalangeal formula (as preserved) is 2-23-3-4 (Figure 7). However, there are many more phalanges in the complete forelimb of the rhomaleosaurid Meyerasaurus (phalangeal formula $=3$ 5-8-8-7; Smith and Vincent, 2010), suggesting that many distal phalanges are probably missing from the holotype of Atychodracon. In the photographs of BRSMG Cb 2335 the left forelimb is also visibly incomplete (Swinton, 1948, plate 11). The phalanges are arranged in five distinct digits but the bones in adjacent digits are staggered relative to each other, much like bricks in a wall. The phalanges gradually decrease in size distally. The most distal phalanges in digits ii and iii appear to be incomplete and their outlines, although indicated by paint, are unclear from the cast.

Other notable characters of BRSMG Cb 2335. The above description covers aspects of BRSMG $\mathrm{Cb} 2335$ that are present, to certain degrees, in the casts. However, for the sake of completeness, it is worth listing some additional notable characters of the postcranial skeleton (Figure 1) as provided by previous authors, but that are unrepresented by cast material, and so have not been described above (see also Table 1). Swinton (1948) noted the total length of the skeleton as $4960 \mathrm{~mm}$. This is similar to Stutchbury (1846) and Sollas (1881) who both measured 16 feet 3 inches $(4953 \mathrm{~mm})$ along its curvature (contra Cruickshank, 1994a, who gave the total length, citing Stutchbury but giving a different measurement, as 16 feet 8 inches or 5080 $\mathrm{mm})$. Swinton (1948) gave the length of the neck as $1370 \mathrm{~mm}$ (and also as $1350 \mathrm{~mm}$, there are two conflicting measurements in the same paper), and the tail approximately $1300 \mathrm{~mm}$ long, slightly shorter than the figure of $1384 \mathrm{~mm}$ given by Sollas (1881). The femur is slightly shorter $(340 \mathrm{~mm}-343$ $\mathrm{mm}$ ) than the humerus, and the tibia and fibula are equal in length (see Table 1). Swinton (1948) counted 30 cervical vertebrae (including the atlas and axis), while Stutchbury (1846) counted only 29 cervicals and Sollas (1881) counted 29-30. This number is similar to LEICS G221.1851, which has about 28 cervical vertebrae, possibly more (Cruick- shank, 1994a), and other rhomaleosaurids, e.g., Macroplata has 26 (Ketchum and Smith, 2010) and Rhomaleosaurus has 28 (Smith and Benson, 2014). Swinton (1948) counted 32 caudals while Stutchbury counted 31 sacral and caudal vertebrae. This number closely matches LEICS G221.1851, which has 33-34 caudal vertebrae, and is similar to rhomaleosaurids in general, which possess 29-34 caudal vertebrae (Smith, 2013; Smith and Benson, 2014).

\section{DISCUSSION}

\section{Systematic Position}

All previous systematic analyses of plesiosaurs have demonstrated that 'Rhomaleosaurus' megacephalus does not belong to Rhomaleosaurus sensu stricto (see Smith and Benson, 2014, for a summary). Smith (2007) and Smith and Dyke (2008) found 'R.' megacephalus in a sister relationship with Eurycleidus arcuatus and therefore followed Andrews (1922) by formally reassigning 'Rhomaleoaurus' megacephalus to the genus Eurycleidus, suggesting that the differences between Eurycleidus arcuatus and 'Rhomaleosaurus' megacephalus did not justify generic separation. Benson et al. (2013b) also resolved these taxa in a sister relationship, and Ketchum and Benson (2011) found them in a close paraphyletic relationship, confirming their close kinship. However, Benson et al. (2012) found them in a polyphyletic relationship suggesting generic distinction. Direct comparison between the taxa is limited because the cranium is unknown in Eurycleidus. Note that a specimen from the Sinemurian of Lyme Regis (OUM J.28585) referred to Eurycleidus by Cruickshank (1994c) differs from the type material of Eurycleidus and may represent a new taxon (O'Keefe, 2004), so OUM J.28585 is omitted from this discussion. Nevertheless, detailed reanalysis of BRSMG Cb 2335 has revealed several differences between it and the holotype of Eurycleidus. These can be summarised as follows: 1. A midline cleft on the ventral surface of the mandibular symphysis is bordered by the splenials posteriorly in BRSMG Cb 2335 but not in Eurycleidus. 2. The splenials are separated on the midline by an additional large asymmetrical cleft in Eurycleidus. 3. The preaxial margin of the humerus is straight in BRSMG Cb 2335, whereas it is concave in Eurycleidus. 4. The humerus is more stout and robust in BRSMG Cb 2335 compared to Eurycleidus. 5. The ulna is shorter than the radius in BRSMG Cb 2335 whereas the ulna is longer than the radius in Eury- 
cleidus. BRSMG Cb 2335 and Eurycleidus share many characters and the two are clearly closely related, but the differences listed can be regarded as sufficient to justify generic distinction, in accordance with the results of some recent cladistic analyses (Benson et al., 2012).

\section{The Barrow Kipper (LEICS G221.1851)}

Neotype specimens should only be erected in the absence of a diagnostic holotype, i.e., when "a name-bearing type is necessary to define the nominal taxa objectively" (ICZN Article 72.1, International Commission on Zoological Nomenclature, 1999 , p. 84), which was not the case for 'P.' megacephalus because of the diagnostic descriptions, photographs, illustrations, and casts of BRSMG Cb 2335 described herein. The specimen designated as the neotype of 'Rhomaleosaurus' megacephalus by Cruickshank (1994a) (LEICS G221.1851) is from the Bottom Floor Limestone, Lower Lias Group, (Planorbis sub-zone of the Psiloceras planorbis zone), Lower Hettangian, Barrow-upon-Soar, Leicestershire, UK, and the specimen history is outlined by Cruickshank (1994a, 1994b). Additional interpretations of LEICS G221.1851 have been provided by O'Keefe (2001, figure 8), Druckenmiller (2006, figure 4.20), and Smith (2007). Phylogenetic analyses including BRSMG Cb 2335 and LEICS G221.1851 as separate entities (Smith and Dyke, 2008) do not conflict with Cruickshank's proposal that these specimens represent the same taxon, so LEICS G221.1851 is referred to Atychodracon. However, a thorough description of LEICS G221.1851, as well as several other specimens tentatively referred to this taxon (NMING F10194, F8749), is required to fully understand the generic and specific diversity among these early large-bodied rhomaleosaurids.

\section{Use of Casts in Systematic Descriptions}

The historical casts described above provide valuable three-dimensional data, including diagnostic information, on the original holotype specimen that they represent (BRSMG Cb 2335). This demonstrates that casts can have an important role to play in systematic palaeontology: they can be described, measured, and coded into cladistic or morphometric data matrices (e.g., Smith, 2007; Smith and Dyke, 2008). This is especially valuable when the original material is lost, damaged or destroyed. The ICZN regulates type specimens based on illustrations or descriptions (Article
72.5.6), but not type specimens based on threedimensional representations, either physical or digital. The ICZN also recognises casts (and moulds) as eligible name-bearing types when they are "natural" (ICZN article 72.5.3, p. 77). I would therefore urge the ICZN to consider either expanding article 72.5.6 to include three-dimensional representations (in addition to the two dimensional illustrations and descriptions already regulated), where the name bearing type is not the cast itself but the specimen it represents; or to expand article 72.3.3 to include 'artificial' casts and moulds, which are functionally no different from natural ones. This will help formalise the use of casts and other 3D representations, including digital ones, in systematic descriptions when the original fossil material is lost or destroyed.

\section{ACKNOWLEDGEMENTS}

I thank P. Shepherd, L. Neep, M. Howe, and S. Harris (BGS), P.W. Jackson (TCD), and $S$. Chapman (NHMUK) for assistance and access to material in their care. M. Parkes (NMING), M. Evans (LEICS), and J. Radley (WARMS) provided access to comparative material. I. Gladstone (BRSMG) shared information from the BRSMG archives. Students D. Gill and Y. Yonan laser scanned the BGS material under the supervision of S. Harris (BGS). S. Nikolaeva and N. Evenhuis (ICZN) provided advice on the nomenclature. $M$. Evans and R. Forrest provided helpful discussion and advice on an early draft of this paper, and three anonymous reviewers provided additional comments on a later draft.

\section{REFERENCES}

Andrews, C.W. 1922. Description of a new plesiosaur from the Weald Clay of Berwick (Sussex). Quarterly Journal of the Geological Society, London, 78:285298.

Benson, R.B.J., Evans, M., and Druckenmiller, P.S. 2012. High diversity, low disparity and small body size in plesiosaurs (Reptilia, Sauropterygia) from the Triassic-Jurassic boundary. PLoS ONE, 7:e31838.

Benson, R.B.J., Evans, M., Smith, A.S., Sassoon, J., Moore-Faye, S., Ketchum, H.F., and Forrest, R. 2013a. A Giant pliosaurid skull from the Late Jurassic of England. PLoS ONE, 8:e65989.

Benson, R.B.J., Evans, M., and Taylor, M. A. In press. The anatomy of Stratesaurus (Reptilia, Plesiosauria) from the lowermost Jurassic of Somerset, United Kingdom. Journal of Vertebrate Paleontology. 
Benson, R.B.J., Ketchum, H.F., Naish, D., and Turner, L.E. 2013b. A new leptocleidid (Sauropterygia, Plesiosauria) from the Vectis Formation (early Barremian - early Aptian; Early Cretaceous) of the Isle of Wight and the evolution of Leptocleididae, a controversial clade. Journal of Systematic Palaeontology, 11:233-250.

Cruickshank, A.R.I. 1994a. Cranial anatomy of the Lower Jurassic pliosaur Rhomaleosaurus megacephalus (Stutchbury) (Reptilia: Plesiosauria). Philosophical Transactions of the Royal Society of London, Series B, 343:247-260.

Cruickshank, A.R.I. 1994b. A Victorian fossil wholemount technique: A cautionary tale for our times. The Geological Curator, 6:17-22.

Cruickshank, A.R.I. 1994c. A juvenile plesiosaur (Plesiosauria: Reptilia) from the Lower Lias (Hettangian: Lower Jurassic) of Lyme Regis, England: a pliosauroid-plesiosauroid intermediate? Zoological Journal of the Linnean Society, 112:151-178.

de Blainville, H.M.D. 1835. Description de quelques espèces de reptiles de la Californie, précédé de l'analyse d'un système général d'Herpétologie et d'Amphibiologie. Nouvelles Annales du Muséum National d'Histoire Naturelle, Paris, 4:233-296.

Druckenmiller, P.S. 2006. Early Cretaceous plesiosaurs (Sauropterygia: Plesiosauria) from northern Alberta: palaeoenvironmental and systematic implications. Unpublished Ph.D. thesis, Department of Biological Sciences, University of Calgary, Calgary, Alberta.

Druckenmiller, P.S. and Russell, A.P. 2008. A phylogeny of Plesiosauria (Sauropterygia) and its bearing on the systematic status of Leptocleidus Andrews, 1922. Zootaxa, 1863:1-120.

Gasparini, Z. 1997. A new pliosaur from the Bajocian of the Neuquen Basin, Argentina. Palaeontology, 40:135-147.

Gomez-Perez, M. 2004. The palaeobiology of an exceptionally preserved Colombian pliosaur (Sauropterygia; Plesiosauria). Unpublished Ph.D. dissertation, University of Cambridge.

International Commission on Zoological Nomenclature. 1999. International Code of Zoological Nomenclature. Fourth Edition. International Trust for Zoological Nomenclature, London.

Ketchum, H.F. and Benson, R.B.J. 2011. A new pliosaurid (Sauropterygia, Plesiosauria) from the Oxford Clay Formation (Middle Jurassic, Callovian) of England: evidence for a gracile, longirostrine grade of Early-Middle Jurassic pliosaurids. Special Papers in Palaeontology, 86:109-129.

Ketchum, H.F. and Smith, A.S. 2010. The anatomy and taxonomy of Macroplata tenuiceps (Sauropterygia, Plesiosauria) from the Hettangian (Lower Jurassic) of Warwickshire, United Kingdom. Journal of Vertebrate Paleontology, 30:1069-1081.

Kuhn, O. 1961. Die Familien der Rezenten und fossilen Amphibien und Reptilien. Verlagshaus Meisenbach, Bamberg.
Lydekker, R. 1889. Catalogue of the Fossil Reptilia and Amphibia in the British Museum, Part II. Containing the Orders Ichthyopterygia and Sauropterygia. Taylor and Francis, London.

O'Keefe, F.R. 2001. A cladistic analysis and taxonomic revision of the Plesiosauria (Reptilia: Sauropterygia). Acta Zoologica Fennica, 213:1-63.

O'Keefe, F.R. 2002. The evolution of plesiosaur and pliosaur morphotypes in the Plesiosauria (Reptilia: Sauropterygia). Paleobiology, 28:101-112.

O'Keefe, F.R. 2004. Preliminary description and phylogenetic position of a new plesiosaur (Reptilia: Sauropterygia) from the Toarcian of Holzmaden, Germany. Journal of Paleontology, 78:973-988.

O'Keefe, F.R. and Carrano, M.T. 2005. Correlated trends in the evolution of the plesiosaur locomotor system. Paleobiology, 31:656-675.

Owen, R. 1860. On the orders of fossil and recent Reptilia, and their distribution in time. Report of the British Association for the Advancement of Science for 1859, 29:153-166.

Smith, A.S. 2007. Anatomy and systematics of the Rhomaleosauridae (Sauropterygia, Plesiosauria). Ph.D. thesis, University College Dublin.

Smith, A.S. 2013. Morphology of the caudal vertebrae in Rhomaleosaurus zetlandicus and a review of the evidence for a tail fin in Plesiosauria. Paludicola, 9:144158.

Smith, A.S. and Benson, R.B.J. 2014 . Osteology of Rhomaleosaurus thorntoni (Sauropterygia, Rhomaleosauridae) from the Lower Jurassic (Toarcian) of Northamptonshire, England. Monograph of the Palaeontographical Society, London. 168 (642):1-40.

Smith, A.S. and Dyke, G.J. 2008. The skull of the giant predatory pliosaur Rhomaleosaurus cramptoni: implications for plesiosaur phylogenetics. Naturwissenschaften, 95:975-980.

Smith, A.S. and Vincent, P. 2010. A new genus of pliosaur (Reptilia: Sauropterygia) from the Lower Jurassic of Holzmaden, Germany. Palaeontology, 53:1049-1063.

Sollas, W.J. 1881. On a new species of Plesiosaurus ( $P$. conybeari) from the Lower Lias of Charmouth; with observations on $P$. macrocephalus, Stutchbury, and $P$. brachycephalus, Owen. Quarterly Journal of the Geological Society, London, 37:440-480.

Storrs, G.W. and Taylor, M.A. 1996. Cranial anatomy of a new plesiosaur genus from the lowermost Lias (Rhaetian/Hettangian) of Street, Somerset, England. Journal of Vertebrate Paleontology, 16:403-420.

Stutchbury, S. 1846. Description of a new species of Plesiosaurus, in the Museum of the Bristol Institution. Quarterly Journal of the Geological Society, 2:411417.

Swinton, W.E. 1930. The plesiosaurs in the Bristol Museum. Report of the British Association for the Advancement of Science, 1930: 340-341. 
Swinton, W.E. 1948. Plesiosaurs in the City Museum, Bristol. Proceedings of the Bristol Naturalists' Society, 27:343-360.

Taylor, M.A. 1992. Functional anatomy of the head of the large aquatic predator Rhomaleosaurus zetlandicus (Plesiosauria, Reptilia) from the Toarcian (Lower Jurassic) of Yorkshire, England. Philosophical Transactions of the Royal Society of London B, 335:247280.

Taylor, M.A. 1994. The plesiosaur's birthplace: the Bristol Institution and its contribution to vertebrate palaeontology. Zoological Journal of the Linnean Society, 112:179-196.

Taylor, M.A. and Cruickshank, A.R.I. 1989. The Barrow Kipper, 'Plesiosaurus' megacephalus (Plesiosauria, Reptilia) from the Lower Lias (Lower Jurassic) of Barrow-upon-Soar, Leicestershire. Transactions of the Leicester Literary and Philosophical Society, 83:2024.
Vincent, P. and Smith, A.S. 2009. A redescription of Plesiosaurus propinquus Tate \& Blake, 1876 (Reptilia, Plesiosauria), from the Lower Jurassic (Toarcian) of Yorkshire, England. Proceedings of the Yorkshire Geological Society, 57:133-142.

Wright, T. 1860. On the zone of Avicula contorta, and the Lower Lias of the south of England. Quarterly Journal of the Geological Society, London, 1:374-411.

Wyse Jackson, P.N. 2004. Thomas Hawkins, Lord Cole, William Sollas and all: Casts of Lower Jurassic Marine Reptiles in the Geological Museum, Trinity College, Dublin, Ireland, The Geological Curator, 8:11-18. 